\title{
Perinatal Asfiksi İle Prezente Olan Nemalin Miyopatisi
}

\author{
A Nemaline Myopathy Presenting with Perinatal Asphyxia
}

\author{
Nisa Eda Çullas İlarslan'1, Dilek Dilli2, Nihan Hilal Hoșağası'², Beril Talim³, Engin Demir ${ }^{4}$, \\ Ayșe Aksoy ${ }^{5}$, Ayșegül Zenciroğlu², Nurullah Okumuș ${ }^{2}$
}

Ankara Üniversitesi Tıp Fakültesi Çocuk Sağlığı ve Hastalıklar A.B.D, Genel Poliklinik

Dr. Sami Ulus Kadın Doğum, Cocuk Sağığıve Hastalıkları Eğitim ve Araştırma Hastanesi, Neonatoloji Bilim Dalı

Hacettepe Üniversitesi Çocuk Sağlığı ve Hastalıkları A.B.D, Pediyatrik Patoloji Bilim Dalt

Dr. Sami Ulus Kadın Doğum, Çocuk Sağlığı ve Hastalıkları Eğitim ve Araștirma Hastanesi

Arastırma Hastanesi Çocuk Nörolojisi Bilim Dalı
Geliș tarihi : 09.06.2015 • Kabul tarihi: 23.10.2015

iletișim

Uzm. Dr. Nisa Eda Çullas ilarslan

Tel: 03125955763

Faks: 03123191440

E-posta: md.eda@hotmail.com

Ankara Üniversitesi Tıp Fakültesi Cocuk Sağlığı ve Hastalıkları A.B.D Dikimevi/Cebeci- Ankara 06100

Nemalin miyopatisi değișik derecelerde ve genellikle ilerleyici olmayan veya yavaș ilerleyici kas güçsüzlüğü ile karakterize, nadir görülen herediter bir nöromusküler hastalıktır. Klinik bulgular esas olarak yaygın kas güçsüzlüğü ve hipotoni ile ilișkilidir. Hastalar ağır hipotoni nedeniyle asfiktik doğabilir. Hemen tamamında zamanla solunum ve beslenme yetersizliği gelișir. Uzun ince yüz görünümü, yüksek damak, pektus ekskavatum, skolyoz, ayak deformiteleri ve eklem kontraktürleri gibi bulgular tabloya eșlik edebilir. Kesin tanı kas biyopsisinde Gomori trikrom boyasıyla kas liflerinde kırmızı-mor "çubuk" benzeri nemalin cisimciklerinin saptanmasıyla konulur. Bu yazıda perinatal asfiksi ile prezente olan ve kas biyopsisi ile nemalin miyopatisi tanısı alan bir yenidoğan olgu literatür bilgileri ıșığında sunuldu.

Anahtar Sözcükler: Asfiksi, Hipotoni, Nemalin Miyopatisi, Yenidoğan.

Nemaline myopathy is a rare hereditary neuromuscular disease characterized by variable degree of non-progressive or slowly progressive generalized muscle weakness. Clinical features are mostly related with muscle weakness and hypotonia. Patients may present with birth asphyxia as a result of severe hypotonia. Respiratory insufficiency and feeding difficulty develop eventually in the majority of cases. Narrow and elongated face, high arched palate, pectus excavatum, scoliosis, foot deformities, and joint contractures may also be present. Definite diagnosis of Nemaline myopathy is possible by a muscle biopsy in which modified Gomori-trichrome stain indicates the presence of purple-red colored rod-like structures called "nemaline bodies" in the muscle fibers. Here a newborn who presented with birth asphyxia and diagnosed as nemaline myopathy with muscle biopsy is reported and discussed in the light of literature.

Key Words: Asphyxia, Hypotonia, Nemaline Myopathy, Newborn.

Nemalin miyopatisi (diğer adıyla nemalin rod miyopatisi) değişik derecelerde ve genellikle ilerleyici olmayan kas güçsüzlüğü ile karakterize nadir görülen bir konjenital, herediter ve nöromusküler hastalıktır. İlk kez 1963 yılında Shy ve Conen tarafindan tanımlanmıştır (1). Hastalığın siklığının 1/50.000 olduğu tahmin edilmektedir (2).

Konjenital miyopatiler heterojen bir grup nöromusküler hastalık olup sarkomerik proteinleri kodlayan çeşitli genlerdeki mutasyonlardan kaynaklanmaktadir (3). Nemalin miyopatisi konjenital miyopatilerin s1k görülen tiplerinden biridir (4). Bugün hastalık iyi tanımlanan bir antite olup hastalığın patogenezinden sorumlu çok saylda gen defekti bildirilmiştir.

Klinik bulgular esas olarak yaygın kas güçsüzlüğü ve hipotoni ile ilişkilidir. Hastalar ağır hipotoni nedeniyle asfiktik doğabilir (5). Zamanla solunum ve beslenme yetersizliği gelişir. Uzun ince yüz görünümü, yüksek damak, pektus ekskavatum, skolyoz, ayak deformiteleri ve eklem kontraktürleri gibi bulgular eşlik edebilir (6). Kas biyopsisinde gomori-trikrom boyasiyla kas liflerinde kırmız1-mor cisimciklerin saptanması tanısaldır (2). Bu yaz1da perinatal asfiksi ile prezente olan ve kas biyopsisi ile nemalin miyopatisi tanısı alan bir yenidoğan olgu sunuldu.

\section{OLGU SUNUMU}

Olgunun dış merkezde, 23 yaşındaki gravida 3, parite 2, abortus 1 , yaşayan 2 anneden 39. gebelik haftasinda vajinal yolla 2500 gr ağırlı̆̆ında mekonyumlu doğduğu öğrenildi. Bebeğin 1. ve 5. dk APGAR skorlarının sirasiyla 1 ve 5 olduğu bildirildi. Spontan solunumu olmaması nedeniyle doğum salonunda derin trakeal aspirasyon, pozitif basınçlı ventilasyon ve entübasyon uygulandığı öğrenilen hasta, 
postnatal 2. gününde, yenidoğan yoğun bakım ünitemize mekonyum aspirasyon sendromu (MAS) ve perinatal asfiksi ön tanilariyla entübe halde kabul edildi. Düzenli gebelik takibi yapilan annenin; rutin ultrasonografide azalmış fetal hareketler, polihidramniyoz ve eklem kontraktürü görülmemişti. Doğuma kadar fetal kalp hızı monitorizasyonunda fetal bradikardi tesbit edilmemişti. Doğum esnasında perinatal asfiksiye yol açabilecek uterin rüptür, plasental dekolman veya umbilikal kord prolapsusu gibi bir komplikasyon bildirilmemişti. Anne doğum sonrasinda sorguland1ğında gebeliğin son iki gününde bebek hareketlerinin azaldığını fark ettiğini belirtti. Anne-baba arasinda üçüncü derece akrabalık olduğu ve ailede bilinen kas hastalığ1 öyküsü olmadığ1 ögrrenildi.

İlk muayenede yaygin hipotoni, derin tendon reflekslerinde belirgin azalma, her iki elde ulnar deviasyon, göğüs deformitesi ve yüksek damak dikkati çekti. Dilde fasikülasyon izlenmedi.

Hastanın doğduğu merkezde umbilikal kord $\mathrm{pH}$ ile yaşamin ilk saatlerinde arter kan gazı ve kas enzimi ölçümlerinin yapılmadığı öğrenildi. Postnatal ikinci günde kliniğimizde yapılan laboratuvar incelemelerinde kas enzimlerinde anlamlı yükseklik saptanmadı. Kreatin kinaz [(CK:550 U/L (N: $87-$ $725 \mathrm{U} / \mathrm{L})$, yaşamın ilk 72100.saatinde)] , laktat dehidrogenaz [(LDH:604 IU/L (N:170-580 U/L)] idi ve değerler günler içerisinde giderek geriledi (postnatal 4. gün CK:221 U/L, LDH: 401 IU/L). Hastanın hipotonisitesinin yanı sıra eşlik eden diğer bulguları nedeniyle yapılan tetkiklerinde; metabolik tarama testleri ve tiroid fonksiyonları normal olarak sonuçlandi. Oftalmolojik muayenede özellik yoktu. Ekokardiyografide dekstrokardi dışında patoloji saptanmadi. Kromozom analizi normal olup, tip 1 spinal musküler atrofi yönünden SMN1 geninde mutasyon saptanmadi.

Hipotonisitesi devam eden ve ventilatörden ayrılamayan hastanın ağzında ters $\mathrm{V}$ görünümü ve ekstremitelerinde yaygin kontraktürler gelişti (Şekil-1). Postnatal yirminci günde sağ bacakta kontraktüre ikincil femur kırığı oluştu ve atele alındi.

Hipotoni nedeninin aydinlatılmasina yönelik olarak yapılan kas biyopsisinde; kas lifleri arasında çap farkı ve gomori-trikrom boyasında nemalin cisimcikleri ile uyumlu birçok lifte kırmız1-mor renkli birikimler saptand (Resim-2). Kas biyopsisiyle nemalin miyopatisi tanısı alan hastadan genetik inceleme için kan örneği alındı ancak teknik nedenlerle test yapilamadi.

Solunum, enfeksiyon kontrolü ve beslenme yönünden destek tedavileri ve-

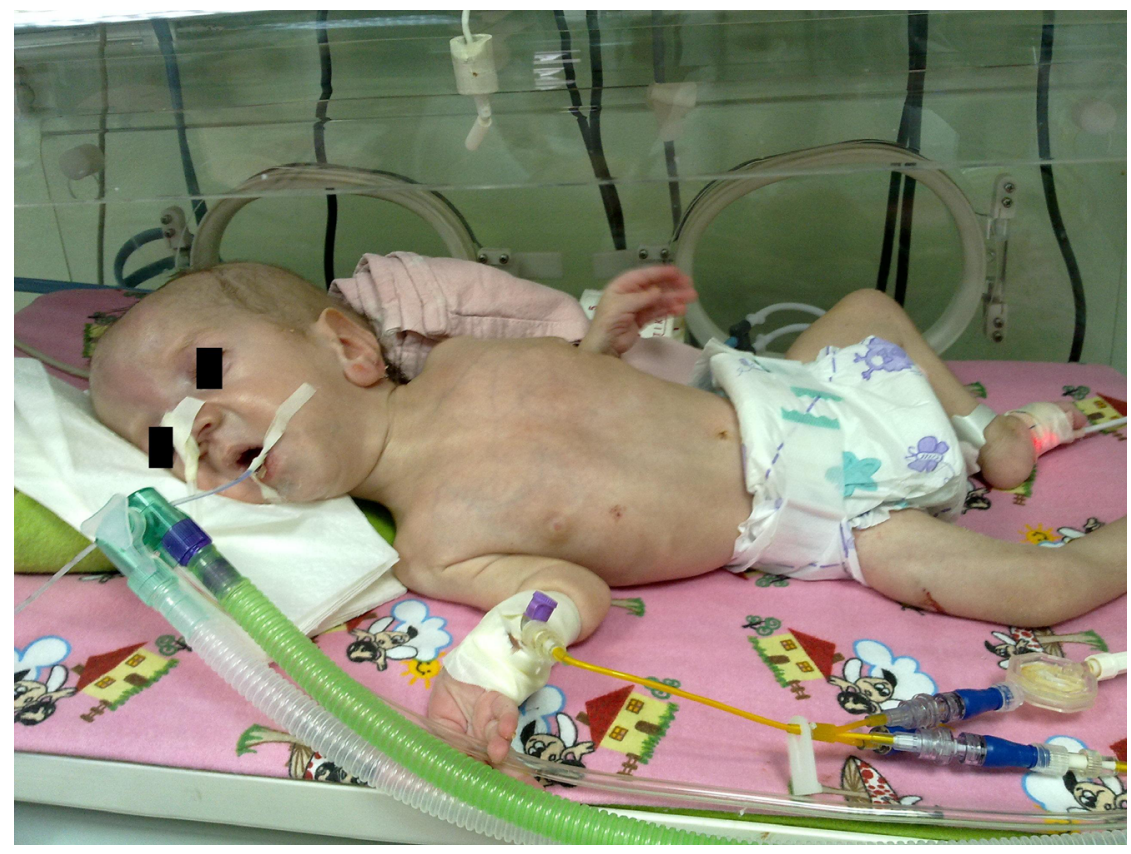

Şekil-1: Olgunun fiziksel görünümü. Uzun ince yüz, ağızda ters "V" görünümü, kurbağa pozisyonu, ekstremite kontraktürleri görülmekte.

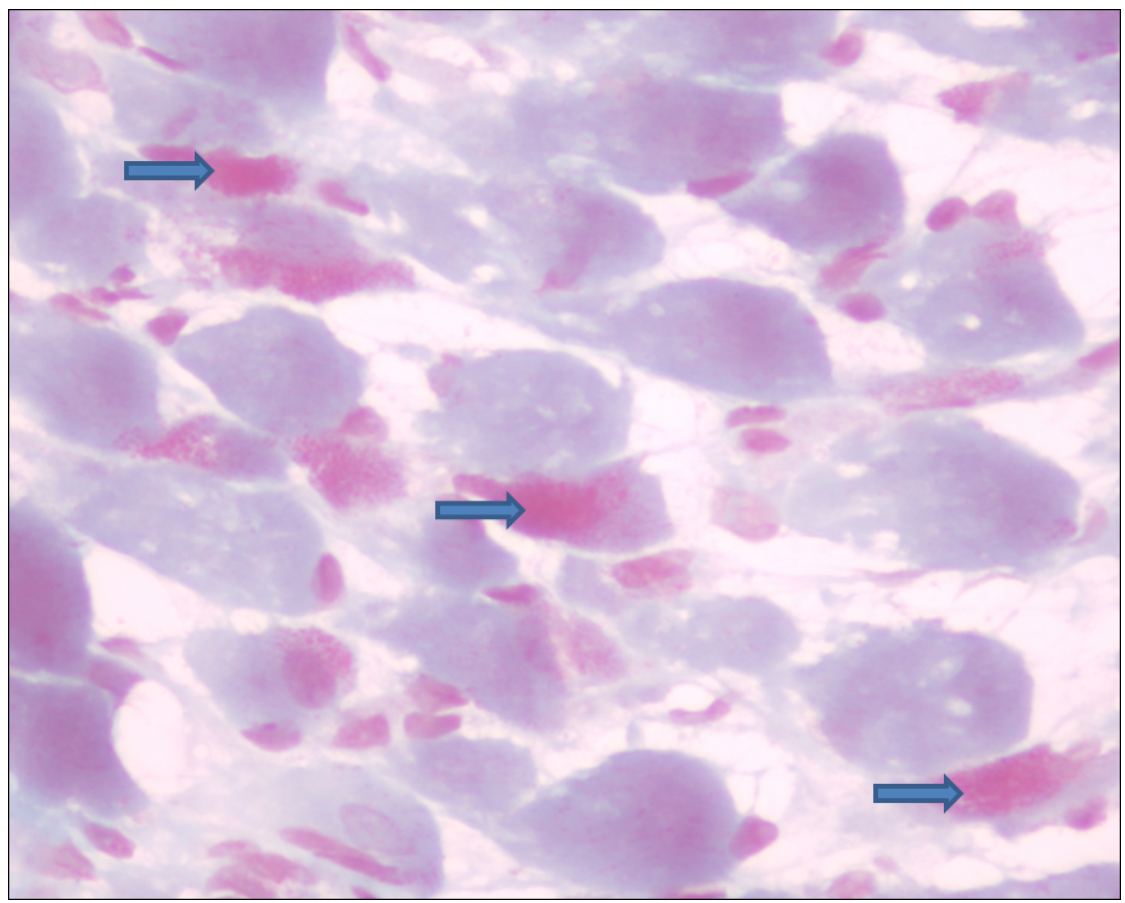

Şekil-2: Kas biyopsisi. Gomori trikrom boyası ile çok sayıda kırmızı-mor renkli birikimler (nemalin rodlar). 
rilen hastanin takibinde trakeostomi ve gastrostomi açıldı. Ventilatör bağımlllı̆̆1 devam eden hasta postnatal yedinci ayda pnömoni ve solunum yetmezliği nedeniyle kaybedildi.

\section{TARTIȘMA}

Nemalin miyopatisi; özellikle yüz, boyun ve gövde fleksör kasları, ayak dorsifleksör kasları ve parmak ekstensör kaslarını tutan; yaygin hipotoni ve kas güçsüzlüğü ile karakterize bir konjenital miyopatidir $(1,6)$. Kas güçsüzlüğü her ne kadar yaygin olsa da solunum kasları gibi bazı kaslardaki güçsüzlük daha belirgin olabilmektedir (7). Hastalar hipotoniye bağlı ciddi solunum ve beslenme yetersizliği bulguları gösterirler. Ayn zamanda bizim olgumuzda olduğu gibi uzun ince yüz, yüksek damak, pektus ekskavatum, skolyoz, ayak deformitesi ve eklem kontraktürleri görülebilir (6).

Hastalığın tanısında öncelikle detaylı bir öykü alınmalıdır. Tüm konjenital miyopatilerde olduğu gibi gebelikte azalmış fetal hareketler; fetal ultrasonografide polihidramniyoz, eklem kontraktürleri, fetal bradikardi; prematür doğum, doğum asfiksisi, malprezentasyon, soygeçmişte aile öyküsü ve anne-baba arasinda akrabalık sorgulanmalıdır. Fizik incelemede özellikle proksimal kaslarda daha belirgin olan yaygin hipotoni, derin tendon reflekslerinde azalma ve hastalığa ilişkin önceden bahsedilen klinik bulgulara dikkat edilmelidir. Laboratuvar incelemelerinde serum CK düzeyi normal veya hafif yükselmiştir $(2,7,8)$. Ancak, konjenital miyopatili hastalarda perinatal asfiksi riskinin artmış olduğu ve asfiktik yenidoğanlarda yüksek CK düzeyleri ile karşılaşılabileceği unutulmamalıdır. Olgumuzda, perinatal asfiksi öyküsü mevcut olmasina rağmen, hipotonisinde düzelme görülmemesi ve ek fizik muayene bulgularının saptanması nedeniyle konjenital miyopati ön tanısı düşünüldü.

Nemalin miyopatili hastalarda elektromiyografi (EMG) bulguları üç yaş öncesinde hafif miyopatik patern göstermekte olup özellikle ilk aylarda uygulanması teknik olarak çoğu kez mümkün değildir (2). Olgumuzda da bu nedenle EMG yapilmadi.
Hipotonik bir yenidoğan bebekte konjenital miyopati tanıs1; klinik bulgular ile birlikte; normal ya da hafif yüksek CK düzeyleri ve kas biyopsisindeki karakteristik histopatolojik özellikler ile konulur $(9,10)$. Yunanca "iplik" anlamina gelen "nema" kelimesinden türeyen nemalin miyopatisi, konjenital miyopatiler içinde patogenezi en iyi anlaşılmış olanıdır. Nemalin miyopati, kas liflerindeki sarkomerik ince filamanların bileşenlerini kodlayan genlerin (alfa ve beta tropomiyozin, troponin $\mathrm{T}$, nebulin ve alfa aktinin) veya sarkomerik ince filamanların yapim ve y1kımindan sorumlu olan proteinlerin defektleri sonucunda ortaya çıar (4). Hastalıkla ilişkili genler ince filamanın kontraktil aparatını kodlamakta olduğu için bir ince filaman hastalığ1 olarak kabul edilmektedir (10). Çok ağır etkilenen kasların biyopsisinden kaçınılması ve birden fazla örnekleme yapılması önerilmektedir. Iş1k mikroskobunda gomoritrikrom boyamasinda "nemalin rod (çubuk)" cisimcikler görülür (1). Bu boyama ile çubuklar mavi-yeşil olan miyofibriler alanda kırmızı renkte boyanırlar. Bu çubukların miyofibriller arasındaki dağılımı rastgele olmakla birlikte siklikla sitoplazma içinde subsarkolemmal alanda ve nükleus etrafinda; nadiren de nükleus içinde yer alırlar. Klasik hematoksilen-eozin boyasıly görülmezler. Biyopside saptanan çubuk sayısı ile klinik şiddet arasinda bir korelasyon bulunmamaktadır (11). Bazen, yenidoğanlarda olduğu gibi, liflerin çok küçük olduğu durumlarda 1 şı 1 mikroskobisinde nemalin rod cisimcikleri fark edilemeyebilirler. Bu gibi durumlarda elektron mikroskobide elektron dens çubuklar şeklinde izlenirler (12). Bu çubuklar Z-diskler ile yapısal devamlilık göstermekte olup disklerin kalınlığında artışa neden olurlar. Aynı zamanda tip 1 lif hakimiyeti ve asit fosfataz aktivitesinde artış görülebilir. Asit fosfataz aktivitesindeki artış, lizozomal enzim aktivasyonu ve hücresel y1kımı tetikleyen bir dejeneratif süreci düşündürür (6). Olgumuzda da hipotoni nedeninin aydınlatılmasına yönelik olarak yapılan kas biyopsisinde kas lifleri arasinda çap farkı mevcut olup, gomori-trikrom boyasında birçok lifte nemalin rodla uyumlu kırmızı-mor renkli birikimler saptand.
Hastalik, ENMC (European Neuromuscular Center) Uluslararas1 Nemalin Miyopatisi Konsorsiyum'u tarafindan altı klinik kategoriye ayrilmıştır (13). Alt gruplar klinik bulguların başlangıç zamanı ve klinik tutulumun derecesi dikkate alınarak tanımlanmıştır: 1) Ağır konjenital form 2) Orta şiddetli konjenital form 3) Tipik form 4) Çocukluk çağında başlayan hafif form (Juvenil Form) 5) Erişkin form (sıklıkla HIV veya monoklonal gammapati ile ilişkili) 6) Diğer formlar (ör: oftalmopileji, kardiyomiyopati).

Ağır konjenital form olguların \%16'sını oluşturur ve en ağır tiptir (2). Doğumda spontan hareketler ve solunum yoktur. Kontraktürler ve konjenital kırıklar olabilir. Bu formun diğer önemli özellikleri yüksek damak, kardiyomiyopati ve oftalmopilejidir. Ara konjenital formda $(\% 20)$ ise doğumda spontan solunum ve hareket mevcuttur. Hastalar erken çocukluk çağında solunum cihazına ihtiyaç duyar, oturamaz, yürüyemezler ve kontraktürler hastalığın erken evresinde oluşmaya başlar. Solunum yetmezliği veya pnömonilere bağlı olarak yaşamin ilk hafta veya aylarında ölüm sıktır (10). Tipik form $(\% 46)$ en sık görülen formdur. Erken çocukluk çağında boyun fleksörlerinde, bulbar, fasiyal ve solunum kaslarında güçsüzlük ile karakterizedir. Distal kas tutulumu da hastalığın geç döneminde tabloya eklenir ve motor gelişim basamakları gecikir. Juvenil formda ise fasiyal tutulum görülmez, diğer bulgular tipik form ile örtüşür. Hastalığın erişkin dönemde tanımlanmış formunun yanı sira kardiyomiyopati, oftalmopileji ile seyreden formu da mevcuttur. Bizim olgumuz perinatal asfiksiden etkilenmişti ve doğumdan itibaren belirgin hipotonisi mevcuttu. Takibinde kontraktüre ikincil femur kırığı gelişmesi nedeniyle ağır konjenital form olarak kabul edildi. $\mathrm{Bu}$ hastalarda ileri yaşlarda kardiyomiyopati gözlenebilir. Olgumuzda kardiyomiyopati bulgusu yoktu ve saptanan dekstrokardinin koinsidental olduğu düşünüldü.

Nemalin miyopatinin moleküler olarak tanımlanmış tüm formları otozomaldir; çoğu kez otozomal 
resesif, nadiren de otozomal dominant geçiș göstermektedir. De novo dominant mutasyonlar da bildirilmiştir $(4,7)$. Hastalık ile ilgili olarak şu ana kadar tanımlanmış on adet gen defekti ve bu genler ile ilgili çok sayıda mutasyon bulunmaktadır (14). Gen defektlerinin hepsi sarkomerin ince filamanlarındaki proteinlerde yer almaktadır. Bu genler TPM3 (alfa-tropomiyozin) (NEM 1), NEB (nebulin) (NEM2), ACTA-1 (alfa-aktinin) (NEM3), TPM2 (betatropomiyozin) (NEM4), TNNT1 (troponin T) (NEM5), KBTBD13 (BTB domain-protein 13) (NEM6), CFL2 (kofilin 2) (NEM7), KLHL40 (Kelch-benzeri-40) (NEM8); KLHL41 (Kelch benzeri-41) (NEM9) ve LMOD3 (Leiomodin 3) (NEM10)' dur. Genetik olarak test edilen olgularin yarisinı NEB gen mutasyonlar1, \%20'sini ACTA -1 gen mutasyonları oluşturmaktadır (5). Hastalığın genetik heterojenitesi ve

\section{KAYNAKLAR}

1. Shy GM, Engel WK, Somers JE et al. Nemaline myopathy. A new congenital myopathy. Brain. 1963; 86:793810 .

2. North KN, Ryan MM. Pagon RA; et al; editors. Nemaline Myopathy. GeneReviews. Seattle (WA): University of Washington, Seattle; 1993-2014. 2002 Jun 19 [updated 2014 Sep 18].

3. Piteau SJ, Rossiter JP, Smith RG et al. Congenital myopathy with cap-like structures and nemaline rods: case report and literature review. Pediatr Neurol. 2014; 51:192-197.

4. Marttila M, Hanif M, Lemola E et al. Nebulin interactions with actin and tropomyosin are altered by diseasecausing mutations. Skelet Muscle. 2014;4:15.

5. Kawase K, Nishino I, Sugimoto M et al. Hypoxic ischemic encephalopathy in a case of intranuclear rod myopathy without any prenatal sentinel event. Brain Dev. 2015;37:265-269.

6. Youssef NC, Scola RH, Lorenzoni PJ et al. Nemaline myopathy: Clinical, histochemical and immunohistochemical features: Arq Neuropsiquiatr . 2009; 67:886-891. özellikle NEB geninin büyük olmasından dolayı olguların tümüyle genetik incelemesi mümkün olmamıştır. Ancak, yeni kuşak teknolojiler ile daha detaylı inceleme imkanı sağlanmaktadır. Literatürde TPM3 geninde normalde görülen otozomal dominant kalıtım haricinde resesif kalitılan Türk olgular bildirilmiştir (15). Mutasyon saptanan olguların ailelerinde de genetik tarama ve annenin sonraki gebeliklerinde prenatal tanı testinin yapilması önerilmektedir. Olgumuzun genetik analizi yurtdışına gönderildi ancak teknik nedenler ile yapılamadi.

Hastalığın kesin tedavisi mevcut olmayıp, diğer konjenital miyopatilerde olduğu gibi destek tedavileri söz konusudur (16). Multidisipliner bir yaklaşım ile yaşam kalitesinin iyileştirilmesi ve yaşam süresinin uzatılması amaçlanır. $\mathrm{Bu}$ amaçla solunum desteğinin sürdürülmesi, alt solunum yolu

7. Wallgren-Pettersson C, Sewry CA, Nowak KJ et al. Nemaline myopathies. Semin Pediatr Neurol. 2011;18:230-238.

8. Jain D, Sharma MC, Sarkar C et al. Congenital myopathies: a clinicopathological study of 25 cases. Indian J Pathol Microbiol. 2008;51:474-480.

9. Gurgel-Giannetti J, Reed UC, Marie SK et al. Rod distribution and muscle fiber type modification in the progression of nemaline myopathy. J Child Neurol. 2003; 18: 235-240.

10.Nance JR, Dowling JJ, Gibbs EM et al. Congenital myopathies: an update.Curr Neurol Neurosci Rep. 2012; 12:165-74.

11. Malfatti E, Lehtokari VL, Böhm J et al. Muscle histopathology in nebulinrelated nemaline myopathy: ultrastrastructural findings correlated to disease severity and genotype. Acta Neuropathol Commun. 2014; 12;2:44.

12. Yin $\mathrm{X}, \mathrm{Pu} C \mathrm{C}$, Wang $\mathrm{Q}$ et al. Clinical and pathological features of patients with nemaline myopathy. Mol Med Rep. 2014;10:175-82. enfeksiyonlarının agresif tedavisi, ağıdan beslenme mümkün değilse nazogastrik sonda ile veya gastrostomi yoluyla yeterli kalori desteğinin verilmesi, skolyoz veya eklem kontraktürü varlığında ortopedi danışımı ve fizik tedavi desteği önerilmektedir. Tüm hastalarda kardiyak değerlendirme yapılması gerekmektedir, çünkü takipte kardiyomiyopati ve kor pulmonale gelişen az sayıda olgu mevcuttur (17). Hastamızda da bu basamakların hepsi uygulandi.

Sunulan olguda başlangıçta MAS ve perinatal asfiksi düşünülmekle birlikte öykü, klinik bulgular ve kas dokusunun histopatolojik olarak incelenmesi ile nemalin miyopatisi tanisı konuldu. $\mathrm{Bu}$ olgu vesilesiyle perinatal asfiksi ön tanisiyla izlenen hastalarda sebat eden yaygın hipotoni varlığında konjenital miyopatilerin de akılda tutulması gerektiği vurgulanmak istendi.

13. Wallgren-Pettersson C, Laing NG. Report of the 83rd ENMC International Workshop: 4th Workshop on Nemaline Myopathy, 22-24 September 2000, Naarden, The Netherlands. Neuromuscul Disord. 2001;11:589595.

14. Nowak KJ, Davis MR, WallgrenPettersson $\mathrm{C}$ et al. Clinical utility gene card for: Nemaline myopathy. Eur J Hum Genet. 2015; Feb 25. doi: 10.1038/ejhg.2015.12.

15. Lehtokari VL, Pelin K, Donner K et al. Identification of a founder mutation in TPM3 in nemaline myopathy patients of Turkish origin. Eur J Hum Genet. 2008;16:1055-1061.

16. Wang CH, Dowling JJ, North $\mathrm{K}$ et al. Consensus statement on standard of care for congenital myopathies. J Child Neurol. 2012;27:363-382.

17. Nagata R, Kamimura D, Suzuki Y et al. A case of nemaline myopathy with associated dilated cardiomyopathy and respiratory failure. Int Heart J. 2011;52:401-405. 